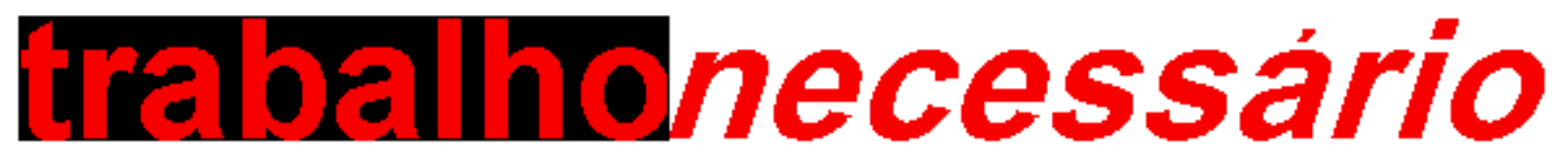

issn: $1808-799 \mathrm{X}$

ano 4 - número 4 - 2006

\title{
DEZ TESES SOBRE AS DIFICULDADES PARA SE FAZER TEORIA EM EDUCAÇÃO NO BRASIL.
}

\section{Luciano Mendes de Faria Filho[i]}

1.ำ Todos sabemos da importância das universidades públicas e, dentre delas, dos programas de Pós Graduação na pesquisa em educação no Brasil. Há também, quase sempre, uma avaliação muito positiva da Pós Graduação como modo de institucionalização da pesquisa científica no país. No entanto, poucas vezes discutimos de forma aprofundada os problemas trazidos por esse modelo de institucionalização da pesquisa no qual os pesquisadores são, também, os responsáveis pelo ensino de graduação, pela administração e pela realização de trabalhos de extensão. Nesse modelo, a alta e contínua sobrecarga de trabalho de docência, administração e extensão a que os pesquisadores em educação estão submetidos é um entrave estrutural à produção de teorias educacionais no Brasil. Talvez devêssemos discutir mais detidamente esse modelo bem como alternativas de saída da sobrecarga que não passem somente pela reivindicação de mais professores, pois os que entrarem correm o risco de acabarem sobrecarregados como os que hoje já estão na universidade.

2.․ Em decorrência do modelo de institucionalização da pesquisa, mas não apenas dele, como veremos, os pesquisadores têm pouco tempo para se dedicarem à pesquisa. No entanto, sabemos que a produção de teorias exige, necessariamente, um tempo "livre" para o amadurecimento da reflexão e, como numa oficina, para o refinamento dos instrumentos básicos de que utilizamos para dar a ver/a ler a nossa produção intelectual: o texto. Os nossos textos não estão ficando apenas cada vez mais pobres do ponto de vista teórico, mas também lingüístico, o que equivale a um duplo ataque ao coração da produção teórica de qualidade.

3.ํImpactados pela falta de tempo, e em decorrência disso, os pesquisadores passam a sentir, também, a falta de tempo para sua própria formação. Se a produção teórica exige necessariamente o domínio do ofício, a maestria, ou seja, exige também uma certa dose de erudição, quer dizer, não basta ao pesquisador dominar as teorias e instrumentos 
necessários á investigação em sua própria área, é também necessário o conhecimento mais ou menos aprofundado de outros domínios afins e, no limite, o tempo "livre" necessário para o passeio pelas mais diversas áreas da produção humana. Estamos assistindo, hoje, à formação de um círculo vicioso em que pesquisadores com baixo nível de formação formam novos pesquisadores que também eles, se especializam muito cedo, antes mesmo de adquirirem os elementos teórico-metodológicos necessários à produção teórica autônoma. A diminuição do tempo médio de titulação nos mestrados e doutorados no país, bem como o aumento da pressão para que os alunos publiquem cada vez mais, em nada contribuem para ao enfrentamento desse problema. Ao contrário, o agravam.

4. A formação deficiente, aliada a uma tradição bastante acentuada entre nós de fazer tabula rasa do nosso passado científico, acaba por produzir um pesquisador que tem grandes dificuldades de dar continuidade às tradições de pesquisa constituídas em suas respectivas áreas. Não tendo se apropriado das tradições, ou seja, da história que o precedeu, e ancorado em uma tradição que lhe assegura que o verdadeiro pesquisador é aquele que rompe com o anterior e propõe "novas abordagens", nossos pesquisadores estão cada vez mais inaugurando o novo sem terem passado pelo velho. No Brasil, o esquecimento das tradições de pesquisa é a regra e isso acarreta a falta de diálogo com os que nos precederam e, no mais das vezes, uma apropriação muito incipiente dos autores clássicos, sobretudo dos autores brasileiros. Não havendo continuidade, a produção teórica em educação encontra dificuldades de estabelecer-se como uma maneira criativa e profunda para se pensar o Brasil.

5. ․ Há que assinalar, no entanto, que o esquecimento dos clássicos das diversas áreas, faz-se acompanhar, por uma apropriação incipiente e pragmática de autores estrangeiros. A subserviência ao outro (estrangeiros) demonstrada pelo esquecimento do nós (brasileiros), implica quase sempre numa dificuldade em pensar com e a incapacidade de discutir os fundamentos das produções com as quais se trabalha. Não raras vezes, esquecemos que o que faz a diferença em relação à produção dos bons autores estrangeiros, nas diversas áreas, é a capacidade ( e necessidade) que têm em estabelecer/produzir vínculos - seja positivo seja negativo - de sua produção com uma tradição de pesquisa em seu país e atuar de modo a inovar sem, no entanto, refutar o diálogo aprofundado com a mesma. Essa subserviência é reforçada pela nossa aceitação em entrar e sustentar "parcerias" acadêmicas com centros de pesquisa no exterior em que as relações são claramente desiguais e, portanto, nas quais a produção teórica dos "outros" é realimentada pela "aplicação" de suas teorias por pesquisadores brasileiros.

6. - Porque não assumimos as nossas tradições e por não fazer delas o ponto de partida para nossas novas interrogações, também temos dificuldade de cultivar hábitos próprios ao debate de um campo acadêmico amadurecido. Os poucos debates acadêmicos existentes, não raras vezes deslocam-se para o plano pessoal, e há uma dificuldade de 
entender que a produção teórica somente é possível com as dúvidas e os questionamentos interpostos pelo outro. Desdobramento desse fator, é nossa dificuldade em fazer com que a arbitragem científica, seja ela relativa a periódicos ou agência de fomento, seja vista como um momento importante de diálogo fecundo em direção a construções teóricas mais refinadas. Os nossos pareceres, via de regra, são burocráticos e não contribuem para a instalação de um clima acadêmico cooperativo entre pares.

7. o esquecimento das tradições, por sua vez, parece ser reforçado pelo modelo de organização da pesquisa no país. São muito recentes a constituição de grupos e a organização de programas de pesquisa que articulem vários projetos. Ainda é regra, mesmo em grupos de pesquisa, a realização de projetos isolados de pesquisa, os quais têm, em geral, curto alcance teórico e são desenvolvidos no curto prazo. A dificuldade que temos em trabalhar junto relaciona-se tanto à dificuldade dos mais novos em estabelecer $\mathrm{e}$ reconhecer a autoridade acadêmica dos pesquisadores mais experientes, quanto com uma ausência de disposição destes em assumir os encargos de coordenar o trabalho dos colegas mais novos. Se a produção teórica de referência exige, necessariamente, tempo para o seu amadurecimento, o qual só vem com o acúmulo de dados e de reflexões produzidos no transcurso das investigações e no debate aprofundado com os pares, o trabalho isolado, em quase todos os domínios, parece conspirar contra a produção teórica de qualidade.

8.․ A dificuldade em estabelecer programas de pesquisa é agravada pelos próprios modelos de financiamento da pesquisa no Brasil. Raramente as agências de fomento estabelecem programas, sobretudo nas áreas das ciências humanas e sociais, que contemplem a necessidade de realização de pesquisas em longo prazo. O tempo e a energia gastos na constante disputa por parcos recursos e, no mais das vezes, a ausência dos mesmos, produz um grande desconforto no pesquisador. No entanto, mais grave ainda é que as condições estruturais para a realização de uma carreira de pesquisador, dentre elas o salário digno e bibliotecas atualizadas, não estão garantidas por nossas instituições. Isso faz com que boa parte dos pesquisadores tenham que desviar o tempo que seria dedicado á pesquisa e à produção de conhecimentos, para a realização de atividades que Ihes garantam o próprio sustento e, muitas vezes, a realização de suas investigações.

9.. Todos estes fatores são agravados e, de certa forma, realimentados pelos modelos de avaliação da produção científica que vêm sendo adotados pelas agências estatais de fomento ou de gestão dos sistemas de ensino e pesquisa do país. É sabido que tais modelos não primam pela valorização da qualidade, da originalidade e da relevância social da produção, o que acaba por reforçar a idéia do "publique ou pereça", idéia essa que encobre o fato de que o perecimento pode estar, contraditoriamente, aliado a uma exacerbação da produção. Longe de avaliar a qualidade da produção, nossos critérios e 
processos avaliativos acabam por legitimar a ampliação do sistema público superior de ensino e pesquisa e de aumento da produtividade dos pesquisadores por meio de uma política perversa, baseada, ao mesmo tempo, na diminuição relativa das verbas e, sobretudo, na intensificação do trabalho dos professores/pesquisadores.

10. - O alardeado crescimento das pesquisas no Brasil, a celebrada criatividade dos pesquisadores brasileiros em trabalhar com parcos recursos e a qualidade de nossa pós graduação, lócus fundamental de formação do pesquisador e de realização das pesquisas, acabam por encobrir um grande voluntarismo, um preocupante adoecimento e um crescente desencantamento dos pesquisadores, sobretudo dos mais novos, fatores estes que comprometem a qualidade da pesquisa e colocam em xeque a nossa capacidade de produzir teorias, de pensar o Brasil e de dialogar de igual para igual com os nossos colegas do mundo inteiro. Mais do que isso: o voluntarismo, o adoecimento e o desencantamento, são sintomas da situação estrutural da produção científica em educação no Brasil, situação esta que longe está de ser resolvida por ações pontuais e sem a ampliação do debate dos pesquisadores com a sociedade brasileira - e não apenas com o Estado - pois é aquela, mais do que este, afinal, quem tem que decidir que parcela da renda nacional quer atribuir para a manutenção, renovação e ampliação da comunidade cientifica brasileira. No entanto, aqui também é preciso que fiquemos atentos, pois se o aumento das verbas para a área é imprescindível, ele não é, porém, suficiente para mudar, por si só, certos padrões culturais que dificultam a produção de teorias em educação no país.

[i] Coordenador do PPGE - Faculdade de Educação - UFMG. Grupo de Estudos e Pesquisa em História da Ec 